As the Presidents See It..

\title{
Nucleation Was More Fun Than Growth
} E.N. Kaufmann, 1985 MRS President

In 1985, whenever my phone rang, it was not uncommon for the caller to be a new MRS volunteer asking, "What is the policy" on such and such. It would not do to tell those familiar with far larger and older societies that we had no policies. What would they think of MRS? So, trusting that as they became more familiar with our unique style, they would realize that volunteers had been making their own rules, I would invent a policy to tide them over. In 1985 we were riding a wave of enthusiasm for the Society's existing and potential contributions to multidisciplinary information exchange-and for the field of materials research per se. Steering-more than long-range planning-was the challenge.

Following on the heels of the presidency of Woody White, who set an unrepeatable standard for energy and dedication, was no easy task. Woody and his predecessors gave us our meetings, proceedings, MRS Bulletin, and a headquarters office, to list just a few ongoing programs. With that underpinning, we were able to nucleate many new activities and practices. For example, IMR was started, with the first issue dated January/February 1986. Publication of MRS Proceedings was transferred from Elsevier to MRS, with the first self-published volume appearing in 1985 . The first real Spring Meeting on the real West Coast was run in San Francisco in April of 1985. (The first "near" Spring Meeting, not quite so far west, was of course in February 1984 in Albuquerque). Democracy in MRS was ushered in with the election of 1985, yours truly having been the last unopposed machine candidate for an officer position.

In 1985, the position of chair for International Relations was created, culminating in the recent formation of IUMRS. MRS Council approved, in principle, a Washington office for MRS which, albeit after an extended gestation, is now up and running. For the U.S. materials community at large, the National Academy Study on Materials Science and Engineering was begun in 1985. (You see, nucleation in materials was rampant).

To see the fruits of initiatives realized in real time was by far the most satisfy-

\section{Most remembered, with a great sense of accomplishment and nostalgia, is the camaraderie I enjoyed with energetic, enthusiastic, dedicated, like-minded colleagues.}

ing aspect of the MRS experience in those days. Of course some of the symptoms of a more mature organization did creep in. We had already begun to need professional meeting planning help, legal advice, personnel policies and procedures, auditors, and an external affairs activity to address relations with domes- tic and overseas societies that had begun to notice us.

Most remembered, with a great sense of accomplishment and nostalgia, is the camaraderie I enjoyed with energetic, enthusiastic, dedicated, like-minded colleagues on the road to building a better MRS. To fairly and accurately characterize the state of the materials field then, and the changes that have taken place in the intervening years, is not possible in a short article, or perhaps even a single text. Suffice it to note that the orphan field of 1985 is now well on its way to becoming a parent field for modern technology.

As you have read in the reminiscences of other former officers, and as you read in virtually every candidate's statement for MRS office, the growth of MRS has been the great success-and the greatest challenge-for the Society. I view the accomplishments of more recent volunteer leaders with awe and admiration as they have successfully grappled with our growth. But I can't help sympathizing just a little, for they missed the sheer entrepreneurial fun which was still MRS in 1985.

Elton Kaufmann is associate director of the Strategic Planning Group at Argonne National Laboratory.

\section{A Year of Change Woody White, 1984 MRS President}

Over the past 20 years, the Materials Research Society (MRS) has evolved from an informal group of volunteers which held a single yearly meeting (the Boston Meeting) into what is now the most dynamic technical society in the world. 1984 was an important year in that evolution and, because of everything that was going on, it was a very exciting time to be involved with MRS. I feel fortunate to have had the opportunity to serve as president that year.

I had never heard of MRS until 1978 when I participated in the first MRS symposium on Laser Annealing, one of the most exciting conferences I had ever attended. I was immediately attracted to the Society and later served in a number of capacities, including symposium cochair, meeting chair, vice president, and finally, in 1984, president.

In 1984, virtually everything in the
Society was expanded or changed. Major accomplishments that year included the inaugural "Spring" Meeting (actually in February) held in Albuquerque, New Mexico, where the attendance exceeded our expectations by almost a factor of two. Our first two local sections and two additional university chapters were established that year, and the MRS constitution was amended to recognize both local sections and university chapters. A major upgrade of the MRS Bulletin was begun; preparations were made for the Society to publish the conference proceedings series, and initial discussions concerning the Journal of Materials Research were held. The Publicity and Public Relations Working Group (which later became a committee) was created and began to publicize society activities and, at the end of the year, the External Affairs Committee was established. 